\title{
THE MULTIPLICATION OPERATOR FROM MIXED-NORM TO $n$-TH WEIGHTED-TYPE SPACES ON THE UNIT DISK
}

\author{
YONGMIN LIU AND YANYAN YU
}

Abstract. Let $H(\mathbb{D})$ be the space of analytic functions on $\mathbb{D}$ and $u \in H(\mathbb{D})$. The boundedness and compactness of the multiplication operator from mixed-norm space to $n$th weighted-type spaces on the unit disk are investigated in this paper.

Mathematics subject classification (2010): 47B38, 47B33, 30H05, 30D45, 46E15.

Keywords and phrases: multiplication operator, mixed-norm space, $n$th weighted-type spaces.

\section{REFERENCES}

[1] K. L. Avetis Yan, Hardy-Bloch type spaces and lacunary series on the polydisk, Glasg. Math. J. 49, 2 (2007), 345-356.

[2] K. D. Bierstedt And W. H. Summers, Biduals of weighted Banach spaces of analytic functions, J. Aust. Math. Soc. (Series A) 54, 1 (1993), 70-79.

[3] H. Chen AND M. ZHANG, Boundedness from below of multiplication operators between $\alpha$-Bloch spaces, Canad. Math. Bull. 53, 1 (2010), 23-36.

[4] B. Choz, H. Koo AND W. Smith, Composition operators on small spaces, Integral Equations Operator Theory 56, 3 (2006), 357-380.

[5] F. Colonna And G. EAsley, Multiplication operators on the Lipschitz space of a tree, Integral Equations Operator Theory 68, 3 (2010), 391-411.

[6] R. Douglas, S. Sun And D. Zheng, Multiplication operators on the Bergman space via analytic continuation, Adv. Math. 226, 1 (2011), 541-583.

[7] H. Hedenmalm, B. Korenblum and K. Zhu, Theory of Bergman Spaces, Graduate Text in Mathematics 199, Springer-Verlag, New York, 2000.

[8] S. Li AND S. STEVIĆ, Volterra-type operators on Zygmund spaces, J. Inequal. Appl. 2007 (2007), Article ID 32124, 10 pp.

[9] S. Li AND S. STEVIĆ, Generalized composition operators on Zygmund spaces and Bloch type spaces, J. Math. Anal. Appl. 338, 2 (2008), 1282-1295.

[10] S. Li AND S. STEVIĆ, Products of Volterra type operator and composition operator from $H^{\infty}$ and Bloch spaces to Zygmund spaces, J. Math. Anal. Appl. 345, 1 (2008), 40-52.

[11] S. Li AND S. STEVIĆ, Cesà ro type operators on some spaces of analytic functions on the unit ball, Appl. Math. Comput. 208, 2 (2009), 378-388.

[12] S. Li AND S. STEVIĆ, Integral-type operators from Bloch-type spaces to Zygmund-type spaces, Appl. Math. Comput. 215, 2 (2009), 464-473.

[13] S. Li AND S. STEVIĆ, Products of integral-type operators and composition operators between Blochtype spaces, J. Math. Anal. Appl. 349, 2 (2009), 596-610.

[14] X. LIU AND Y. YU, The product of differentiation operator and multiplication operator from $H^{\infty}$ to Zygmund spaces, J. Xuzhou Norm. Univ. Nat. Sci. Ed. 29, 1 (2011), 37-39.

[15] Y. LiU AND Y. YU, Composition followed by differentiation between $H^{\infty}$ and Zygmund spaces, Complex. Anal. Oper. Theory (2010), DOI 10.1007/s11785-010-0080-7.

[16] K. Madigan And A. Matheson, Compact composition operators on the Bloch space, Trans. Amer. Math. Soc. 347, 7 (1995), 2679-2687.

[17] J. Manhas, Compact differences of weighted composition operators on weighted Banach spaces of analytic functions, Integral Equations Operator Theory 62, 3 (2008), 419-428. 
[18] A. Shields AND D. Williams, Bounded projections, duality, and multipliers in spaces of analytic functions, Trans. Amer. Math. Soc. 162 (1971), 287-302.

[19] S. STEvić, Composition operators between $H^{\infty}$ and the $\alpha$-Bloch spaces on the polydisc, Z. Anal. Anwendungen 25, 4 (2006), 457-466.

[20] S. STEVIĆ, Norm of weighted composition operators from Bloch space to $H_{\mu}^{\infty}$ on the unit ball, Ars. Combin. 88 (2008), 125-127.

[21] S. STEVIĆ, Generalized composition operators between mixed-norm and some weighted spaces, Numer. Funct. Anal. Optim. 29, 7-8 (2008), 959-978.

[22] S. STEVIĆ, Weighted differentiation composition operators from mixed-norm spaces to weighted-type spaces, Appl. Math. Comput. 211, 1 (2009), 222-233.

[23] S. STEVIĆ, Weighted composition operators from mixed norm spaces into weighted Bloch spaces, J. Comput. Anal. Appl. 11, 1 (2009), 70-80.

[24] S. STEVIĆ, On an integral operator from the Zygmund space to the Bloch-type space on the unit ball, Glasg. Math. J. 51, 2 (2009), 275-287.

[25] S. STEVIĆ, Composition operators from the weighted Bergman space to the $n$th weighted spaces on the unit disc, Discrete Dyn. Nat. Soc. 2009 (2009), Article ID 742019, 11 pages.

[26] S. STEVIĆ, On a new integral type operator from the Bloch space to Bloch-type spaces on the unit ball, J. Math. Anal. Appl. 354, 2 (2009), 426-434.

[27] S. STEvić, Products of composition and differentiation operators on the weighted Bergman space, Bull. Belg. Math. Soc. Simon Stevin 16, 4 (2009), 623-635.

[28] S. STEVIĆ, Composition operators from the Hardy space to the $n$th weighted-type space on the unit disk and the half-plane, Appl. Math. Comput. 215, 11 (2010), 3950-3955.

[29] S. STEvić, Composition followed by differentiation from $H^{\infty}$ and the Bloch space to $n$th weightedtype spaces on the unit disk, Appl. Math. Comput. 216, 12 (2010), 3450-3458.

[30] S. STEVIĆ, Weighted differentiation composition operators from $H^{\infty}$ and Bloch spaces to $n$th weighted-type spaces on the unit disk, Appl. Math. Comput. 216, 12 (2010), 3634-3641.

[31] S. STEVIĆ, Weighted differentiation composition operators from the mixed-norm space to the nth weigthed-type space on the unit disk, Abstr. Appl. Anal. 2010 (2010), Article ID 246287, 15 pages, DOI: $10.1155 / 2010 / 246287$.

[32] S. STEVIĆ, On an integral operator between Bloch-type spaces on the unit ball, Bull. Sci. Math. 134, 4 (2010), 329-339.

[33] B. YOUSEFI AND A. KHAKSARI, Multiplication operators on analytic functional spaces, Taiwanese J. Math. 13, 4 (2009), 1159-1165.

[34] M. ZHANG, Boundedness from below of multiplication operators between $\alpha$-Bloch spaces on the unit ball, Acta Math. Sci. Ser. B Engl. Ed. 30, 5 (2010), 1619-1630.

[35] X. Zhang, J. XIAo AND Z. Hu, The multipliers between the mixed norm spaces in $\mathbb{C}^{n}$, J. Math. Anal. Appl. 311, 2 (2005), 664-674.

[36] X. ZHU, Products of differentiation, composition and multiplication from Bergman type spaces to Bers type spaces (English summary), Integral Transforms Spec. Funct. 18, 3-4 (2007), 223-231.

[37] X. ZHU, Volterra type operators from logarithmic Bloch spaces to Zygmund type space, Int. J. Mod. Math. 3, 3 (2008), 327-336.

[38] X. ZHU, Generalized weighted composition operators on weighted Bergman spaces, Numer. Funct. Anal. Optim. 30, 7-8 (2009), 881-893. 